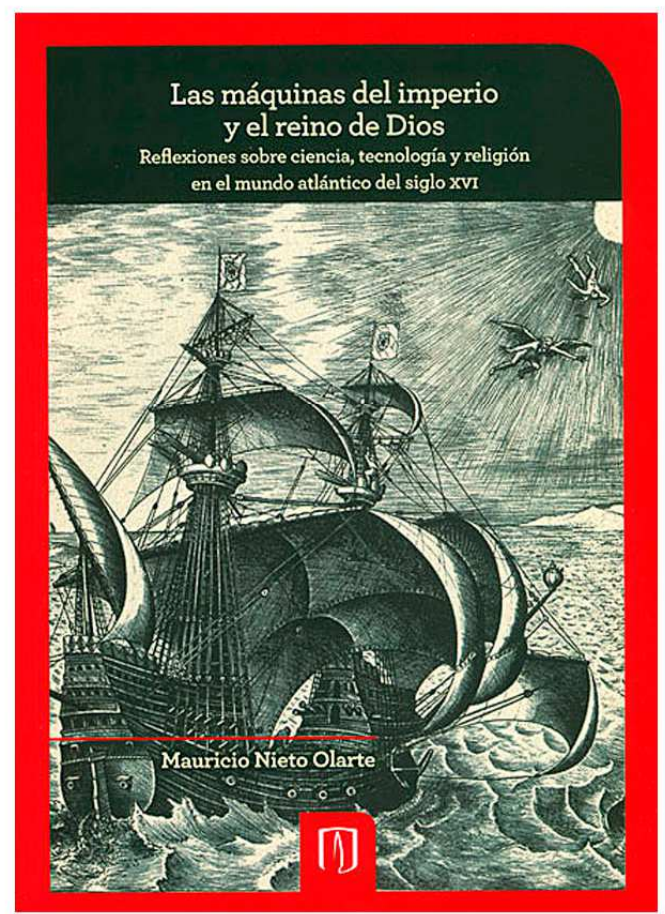

Capa do livro Las máquinas del imperio y el reino de Dios, de Mauricio Nieto Olarte.

\title{
Tiago Bonato
}

OLARTE, Mauricio Nieto. Las máquinas del império y el reino de Dios: reflexiones sobre ciência, tecnologia y religion en el mundo atlântico del siglo XVI. Bogotá: Ediciones Uniandes, 2013.

Mestre e doutorando em História pela Universidade Federal do Paraná. Bolsista Capes.

Amanda Cieslak Kapp

Mestre e doutoranda em História pela Universidade Federal do Paraná. Bolsista Capes. 
KAPP, Amanda Cieslak; BONATO, Tiago. Las máquinas del império y el reino de Dios [resenha]. Domínios da Imagem, Londrina, v. 9, n. 17, p. 277-282, jan./jun. 2015.

ISSN 2237-9126

Recebido em 16/03/2015 e aprovado em 17/06/2015.

OLARTE, Mauricio Nieto. Las máquinas del império y el reino de Dios: reflexiones sobre ciência, tecnologia y religion en el mundo atlântico del siglo XVI. Bogotá: Ediciones Uniandes, 2013.

A conquista de lugares remotos, o controle do comércio ou o estabelecimento de um sistema imperial são, em última análise, um problema de comunicação. Essa é a principal chave de leitura da obra Las máquinas del império y el reino de Dios: reflexiones sobre ciência, tecnologia y religion en el mundo atlântico del siglo XVI, do historiador e filósofo colombiano Mauricio Nieto Olarte, publicada em 2013 e ainda sem tradução para o português. O trabalho objetiva decifrar o problema do conhecimento e do controle à distância, a partir das práticas tecnocientíficas e de sua interação com fatores políticos, religiosos e geográficos na formação dos impérios marítimos ibéricos. Seguindo uma perspectiva historiográfica que discute as relações entre ciência e império, Olarte conclui que as práticas tecnológicas, bem como os artefatos utilizados são parte do império e do poder e não apenas suas ferramentas. Dessa forma o autor coloca em cena barcos, velas, canhões, ventos e correntes marítimas, assim como a ação dos marinheiros, astrônomos, dos demônios e dos santos, das plantas e dos animais. Vale destacar que perde importante, sob essa ótica, questões sobre primazia ou pioneirismo na invenção de uma ciência moderna na Europa. Para o autor, o importante é entender quais foram as práticas que deram lugar a uma forma de conhecimento capaz de permitir o controle de grande parte do mundo.

O capítulo inicial, chamado La Península lbérica y el Atlántico é dedicado, inicialmente, à construção de um histórico acerca da expansão marítima e dos descobrimentos ibéricos, evidenciando razões, aspirações e consequências. Ao tratar dos fatores geográficos da Península enquanto 
KAPP, Amanda Cieslak; BONATO, Tiago. Las máquinas del império y el reino de Dios [resenha]. Domínios da Imagem, Londrina, v. 9, n. 17, p. 277-282, jan./jun. 2015.

ISSN 2237-9126

aliados, o autor destaca não somente o poder natural dos ventos e das correntes, por exemplo, mas o domínio do homem sobre estes e sobre a natureza em geral, por meio do desenvolvimento de diversos saberes e práticas que se desenvolvem nesse contexto.

O segundo capítulo, La burocracia imperial e la apropriación del Novo Mundo, apresenta duas instituições centrais para a organização comercial, administrativa e politica da expansão imperial: a Casa de Contratação e o Real Conselho das Índias, criados, respectivamente, em 1503 e 1524. A primeira delas, localizada em Sevilha, cidade estratégica no momento, funcionava como um centro de informação e um espaço destinado ao controle, de forma centralizada, dos bens do Novo Mundo. Para além de local de armazenamento, era uma instituição complexa, responsável por funções contabilísticas e pelo controle de toda produção náutica espanhola. Assim, entre suas diversas tarefas, que objetivavam a padronização do vasto e diverso conhecimento que vinha sendo produzido, estavam a concessão de licenças para viagens, a organização de registros das embarcações, a organização e inspeção de frotas, o ensino e a avaliação de pilotos, a compilação e a sistematização das rotas, da geografia e das riquezas encontradas, a produção de mapas e cartas de navegação, entre outras. Tais atividades, exercidas por oficiais rigorosamente organizados, eram fiscalizadas pelo Real Conselho das Índias, criado durante o reinado de Carlos $V$, em uma época de franca expansão do império espanhol. Esta segunda instituição foi criada enquanto autoridade autônoma, para supervisionar e regular todas as atividades referentes ao Novo Mundo. Em seu desenrolar, o capítulo demonstra como, na tentativa de controlar os bens e a administração da conquista, ambas as instituições, ao combinarem tarefas e saberes burocráticos, jurídicos, comerciais, cartográficos, náuticos e cosmográficos, contribuíram para a expansão e manutenção do império, que combinava em sua organização administração e burocracia, mas também ciência e tecnologia. 
KAPP, Amanda Cieslak; BONATO, Tiago. Las máquinas del império y el reino de Dios [resenha]. Domínios da Imagem, Londrina, v. 9, n. 17, p. 277-282, jan./jun. 2015.

ISSN 2237-9126

O capítulo a seguir, intitulado El piloto mayor: cosmografía y el arte de navegar, trata, especialmente, dos desafios relacionados com a navegação e, em consequência direta, com a astronomia. Os conhecimentos utilizados até então, principalmente na empresa náutica pelo mar Mediterrâneo, não eram mais suficientes. As novas rotas e configurações geográficas até então inéditas exigiram o desenvolvimento de novas técnicas, mais apuradas e exatas, com destaque para a navegação de altura, baseada em noções astronômicas. Estes conhecimentos foram aperfeiçoados e sistematizados nos manuais de navegação e de cosmografia da época - a principal documentação investigada no capítulo. Por meio da análise de um vasto conjunto de textos desta natureza, Olarte evidenciou questões centrais para a constituição da ciência náutica. Em primeiro lugar, demonstrou a importância do piloto maior, oficial de alto escalão da Casa de Contratação, o qual possuía funções técnicas e científicas, dentre as quais estavam o exame de pilotos, de instrumentos e de rotas e a fabricação de mapas e de cartas de marear atualizadas e seguras. Uma das metas era transformar a experiência dos pilotos em um conhecimento acessível e normatizado, mas que, dependendo da sua natureza, circulava com limitações, em decorrência de razões militares, políticas e econômicas. A seguir, o capítulo se preocupa com o desenrolar das tendências humanistas na Espanha e com a influência na produção do conhecimento náutico, geográfico e astronômico, de autoridades clássicas como Ptolomeu e Aristóteles. A conclusão aborda a contestação e até mesmo a superação dos chamados Antigos, a partir da experiência e das novas descobertas dos exploradores modernos.

O capítulo quatro, Las máquinas del imperio, conforme indica o título, aborda os principais artefatos e instrumentos da navegação ibérica. Olarte não os entende apenas enquanto apetrechos materiais, mas sim como sistemas tecnológicos complexos que funcionam a partir da interação entre homem e natureza. Assim, o grande objetivo é descrever tais artefatos, mas 
KAPP, Amanda Cieslak; BONATO, Tiago. Las máquinas del império y el reino de Dios [resenha]. Domínios da Imagem, Londrina, v. 9, n. 17, p. 277-282, jan./jun. 2015.

ISSN 2237-9126

sempre a partir de sua articulação com elementos naturais e humanos. Da mesma maneira que o anterior, o presente capítulo foi construído a partir do estudo de manuais de navegação. Nestes, o autor pôde perceber o microcosmo que constituía uma nau e a complexa rede de saberes e atividades que caracterizou seu funcionamento. São descritos os principais tipos de barcos, os princípios utilizados em sua engenharia e construção, as peças que os compunham, a preparação necessária para casos de guerra e defesa de corsários, os instrumentos utilizados, como o astrolábio, o quadrante, a balhestilha e a agulha de marear, bem como o porquê de seu uso e o treinamento necessário para tanto, o controle do tempo, a utilização das cartas de marear e das tabelas astronômicas, a divisão da tripulação e a função de cada membro. Por fim, a atenção se volta para a vida a bordo, sempre perpassada pela tônica religiosa que caracterizou todo o empreendimento de expansão.

O quinto capítulo da obra, El Padron Real y la primera cartografia del Nuevo Mundo, se ocupa de um dos produtos tecnológicos que representam de maneira mais explícita o poder europeu sobre o continente americano: os mapas. A cartografia do Renascimento, muito explorada e analisada pela historiografia atual, foi instrumento de uso político e simbólico da posse dos territórios recém descobertos pelos ibéricos. As fontes principais do capítulo são também os manuais de navegação que circulavam dentro e fora da Península no século XVI. A discussão principal parte do grande projeto científico levado a cabo pela Casa de Contratação: a elaboração de um novo mapa do mundo, chamado de Padrón Real, que serviria de base para as navegações e para outros mapas posteriormente produzidos. Com o objetivo de resguardar as descobertas geográficas recentes das outras nações europeias, a cartografia ibérica dos quinhentos é essencialmente manuscrita. O autor demonstra ainda a importância das cartas de marear no processo de navegação ao Novo Mundo. Os mapas do período eram grandes, custosos e pouco práticos para o uso diário. As cartas, dessa forma, 
KAPP, Amanda Cieslak; BONATO, Tiago. Las máquinas del império y el reino de Dios [resenha]. Domínios da Imagem, Londrina, v. 9, n. 17, p. 277-282, jan./jun. 2015.

ISSN 2237-9126

serviram de guia para os navegantes que cruzavam o Atlântico. Grande parte das fontes analisadas reservam um ou mais capítulos para descrever os pormenores da elaboração das cartas de marear, como a forma, as convenções, a toponímia etc. Ao final, Olarte mostra a dificuldade de se levar a cabo um projeto como o Padrón Real, uma vez que ele combinava dois esforços de difícil conciliação: por um lado, ser um padrão e modelo único, e, por outro, incorporar as novas e inúmeras observações geográficas que chegavam à Europa por meio dos escritos, descrições e itinerários de viagens pela América.

O capítulo seguinte, Las criaturas de Dios nunca antes vistas: historia natural, se ocupa da descrição, nomeação e classificação da natureza do Novo Mundo. As fontes utilizadas são as obras de história moral e história natural que circularam pela Europa, descrevendo a natureza e os homens da América àqueles que não empreendiam a viagem transatlântica. Os naturalistas do século XVI faziam parte de uma tradição humanista e seus modelos de interpretação partiam de textos antigos e medievais - como a História Natural de Plínio, O Velho, frequentemente citada - e da Bíblia. Na exploração do Novo Mundo, entretanto, os cânones da erudição europeia não deram conta do exótico mundo natural que se desvelada à medida que o território era conhecido. Mais uma vez o conflito entre tradição e experiência direta, observado em várias frentes do conhecimento na primeira modernidade, se faz presente. O ato de descrever e nomear a natureza americana é para o autor um dos elementos chave do processo de compreensão da América, já que as criaturas do Novo Mundo obrigaram a Europa cristã a construir uma nova forma de entender a natureza. Assim como a cosmografia, a náutica, a cartografia, a história natural foi uma das atividades científicas que expressaram o mesmo propósito de controle e domínio dos novos espaços.

O sétimo e último capítulo do livro, intitulado El Nuevo Mundo, la ciência global y el eurocentrismo, serve como conclusão, e, por isso, nele são 
KAPP, Amanda Cieslak; BONATO, Tiago. Las máquinas del império y el reino de Dios [resenha]. Domínios da Imagem, Londrina, v. 9, n. 17, p. 277-282, jan./jun. 2015.

ISSN 2237-9126

retomados os principais argumentos anteriormente discutidos. A relação entre a Península Ibérica e o surgimento da ciência moderna ganhou espaço na historiografia nos últimos anos. Olarte se posiciona junto aos inúmeros autores que questionam a ideia de que uma revolução científica deu origem a uma nova e única forma de fazer ciência. Segundo ele, mais do que buscar as origens da ciência moderna, seu trabalho busca entender as relações entre conhecimento, tecnologia, religião e império. Essas características são indissociáveis, pois a história da regulamentação administrativa colonial se combina com a história da ciência. Todos os projetos administrativos - a elaboração de mapas, de cartas de marear, de histórias naturais - só foram possíveis graças a um enorme esforço de normatização da experiência, uma vez que de nada serviriam comentários sobre experiências individuais sem códigos estáveis e compartilhados. Duas são as principais conclusões da obra. A primeira está na demonstração convincente de que o Novo Mundo, sua geografia, animais e plantas foram atores ativos e centrais do estabelecimento de uma nova ordem mundial e, portanto, não podem ser reduzidos a mera construção ou invenção europeia. A segunda se encontra na afirmação de que os temas de ordem burocrática, comercial, jurídica, náutica, cartográfica, de história moral e de história natural devem ser entendidos com partes de uma mesma empresa política e religiosa. O Estado imperial católico foi uma organização técnica e científica em que a ciência e a tecnologia estavam a serviço tanto do rei como de Deus. 